\title{
The role of U.S. subprime mortgage-backed assets in propagating the crisis: Contagion or interdependence?
}

\author{
Thomas J. Flavin a , Lisa Sheenan ${ }^{\mathrm{b}, *}$ \\ a Department of Economics, Finance and Accounting, Maynooth University - National University of Ireland \\ Maynooth, Maynooth, Co. Kildare, Ireland \\ b Central Bank of Ireland, Spencer Dock, Dublin 1, Ireland
}

\section{A R T I C L E I N F O}

\section{Article history:}

Received 17 December 2014

Received in revised form 31 August 2015

Accepted 1 September 2015

Available online 13 September 2015

\section{JEL classification:}

G01

G10

G21

\section{Keywords:}

Financial crisis

Contagion

Subprime mortgage-backed securities

Markov-switching VAR

\begin{abstract}
A B S T R A C T
Though relatively small, the subprime mortgage-backed securities market is often identified as the source of the crisis that swept through the U.S. financial system from 2007 onwards. We investigate if its role in the propagation of the crisis was due to contagion or interdependence. Using a Markov-switching VAR with timevarying transition probabilities, we analyse the transmission of shocks across the financial system. We find little evidence of asset correlation changes between normal and crisis regimes and those that do occur are predominantly associated with liquidity variables. Otherwise, relationships are stable across market conditions, implying that the U.S. financial crisis was due to cross-market interdependencies rather than contagion. There is limited evidence that the deteriorating quality of the underlying assets can explain the transition from 'normal' market conditions to a high-volatility regime, although this is not consistent across model specifications.
\end{abstract}

(c) 2015 Elsevier Inc. All rights reserved.

\section{Introduction}

In 2007, increasing uncertainty regarding asset valuations and subsequent losses in the market for subprime mortgage-backed securities heralded the onset of a severe financial crisis. Its repercussions

\footnotetext{
* Corresponding author. Tel.: +35312246835.

E-mail addresses: thomas.flavin@nuim.ie (T.J. Flavin), lisa.sheenan@centralbank.ie (L. Sheenan).
} 
reverberated throughout the entire financial system, affecting stock markets, bond markets (both corporate and sovereign), and short-term funding markets, firstly in the United States and later across much of the international financial system. It is generally accepted that the market for these mortgagebacked securities and other associated complex derivative instruments served as the source of the initial shock that led to the widespread turmoil, see Gorton (2009), Brunnermeier (2008), Dungey, Dwyer, and Flavin (2013), among others. This fledgling market had experienced rapid growth in the five-year period preceding the crisis as investors chased high-yield investment opportunities. The "tranche and ratings" feature of these products appealed to investors, particularly those with a mandate to hold only AAA-rated securities. Initially suppliers of these asset-backed securities struggled to meet the growing demand, leading to increasingly lax lending standards (Mian \& Sufi, 2009) which further fuelled market growth. The share of subprime mortgages increased from approximately $9 \%$ of new mortgages in the early 2000s to over $40 \%$ in 2006 (Hellwig, 2009) and subprime mortgagebacked security issuance almost doubled from $\$ 195$ billion to $\$ 362.5$ billion during the same period (Park, 2010).

However, this market remained a relatively small sector of the overall financial system. Dwyer and Tkac (2009) estimate that, as of December 2006, its value represented approximately $1 \%$ of the total value of global bond markets, stock markets and bank deposits. Therefore a key question that emerges is just how did a shock to this relatively small sector lead to such widespread financial market turmoil? This question is the focus of our paper. In particular, we aim to determine if the spread of the crisis across the financial system was due to financial market contagion or to other predictable factors. We employ an econometric model which allows us to test for two different forms of contagion. ${ }^{1}$ Firstly, we turn to a definition of contagion proposed by Masson (1999a, 1999b), whereby a shock to one market can trigger a system-wide transition to a new, usually bad, equilibrium. We investigate if the subprime mortgage-backed market acted as the driving force behind the transition from tranquil conditions to the recent crisis state. The second, and more often used, definition of contagion operates through the correlation channel. This seeks to distinguish between contagion and market interdependencies. Interdependencies are defined as market correlations that exist in all states of the world and arise due to standard asset market linkages and exposure to common risk sources. Contagion, on the other hand, is a channel that operates only during a crisis or following a large adverse shock. We employ a definition of contagion that is consistent with that of Forbes and Rigobon (2002); namely that contagion occurs when market correlations intensify during a crisis period in excess of what might be expected given the interdependencies that exist during "normal" market conditions. Forbes (2012) distills a number of theoretical channels through which contagion may arise. These include banks and lending institutions; portfolio rebalancing following a shock; wake-up calls; and changes in investor risk aversion. ${ }^{2}$ Banks and lending institutions that experience a negative shock may respond by curtailing the supply of credit to other sectors and/or the real economy. The fact that banks are often highly leveraged tends to amplify the initial shock, as shown by Van Wincoop (2011) and Shin (2012). Investors may undertake portfolio rebalancing following a shock as they sell-off "good" assets to meet cash requirements or to satisfy portfolio weight restrictions. Wake-up calls refer to the tendency of financial market participants to reassess the riskiness of all asset classes following a shock to one asset. This may lead to a period of retrenchment with sales of assets whose perceived risk has grown. Related to this are changes to investors' risk tolerance. Following a shock to one asset, investors may demand a higher risk premium to hold other risky assets, thereby leading to further portfolio rebalancing.

In this paper, we test for contagion from the U.S. subprime mortgage-backed securities market to other sectors of the U.S. financial system during the recent crisis. We track the market for mortgagebacked securities using the ABX.HE indexes (discussed in detail in the next section), which were initially introduced with the aim of adding transparency to this predominantly over-the-counter (OTC) market. The seminal work testing for contagion from the ABX indexes is due to Longstaff (2010) who

\footnotetext{
1 There is little consensus in the academic literature as to what exactly constitutes contagion. Claessens, Dornbusch, and Park (2000), Forbes and Rigobon (2002), Dungey, Fry, González-Hermosillo, and Martin (2010), among others, provide useful overviews of the different definitions used in the literature.

2 Forbes (2012) also includes the international trade channel but we concentrate on different sectors of the U.S. financial system so this is not relevant here.
} 
focuses on the stability of relationships, i.e., the correlation-based approach. We build on this study in a number of important ways. Our first innovation is to employ a different, more suitable, econometric methodology which provides a clearer picture of the shock transmission that characterised the financial system during the crisis period. We argue that the standard vector autoregressive (VAR) approach of Longstaff (2010), which exogenously imposes the crisis period, is not necessarily the best method to measure contagion and we instead estimate a time-varying transition probability Markov-switching VAR (TVTP MS-VAR) model, as developed by Filardo (1994). ${ }^{3}$ This has a number of advantages over the standard VAR. In our specification of the model, we allow both the mean parameters and the asset variances to switch discretely between two regimes. Regimes are determined endogenously by the data, giving a potentially cleaner delineation between the "crisis" and "non-crisis" periods. The regime switch models the heteroskedasticity of asset returns and overcomes the problem of assuming a constant covariance matrix of return innovations. We examine the "correlation channel" of contagion by analysing the stability of cross-market linkages between regimes. In particular, we test if our estimated parameters change as we move from a low- to a high-volatility financial environment. Statistically significant changes indicate instability in cross-market relationships and hence, financial market contagion. If no such changes are detected, then we would conclude that market interdependencies served to propagate the shock. Furthermore, we assess the role of the subprime mortgage-backed market in explaining the transition of the financial system from one state to another. We do this by allowing the time-varying probabilities to depend on asset returns from this sector and test if they add explanatory power over the evolution of the crisis and trigger the turmoil.

Our second contribution is to provide a more holistic picture of the evolving cross-market relationships. Initially, and for comparability with Longstaff (2010), we concentrate on testing for contagion from the subprime mortgage-backed market to government, corporate, money, volatility and equity markets. We then proceed to assess the stability of all other cross-market linkages, thereby building a more complete representation of the financial system during this tumultuous episode. This extension provides some interesting insights into the sources of instability in the U.S. financial system over the crisis period.

We conduct our analysis using the longest available continuously traded ABX index. Although all cross-market correlations intensify during the crisis regime, we find little evidence of contagion from the subprime mortgage-backed asset market to other sectors of the financial system. In fact, most evidence of contagious effects stem from liquidity variables and the VIX market. For robustness, we repeat the analysis using a spliced index (as in Longstaff, 2010) to investigate if our results are sensitive to the changing composition of this index. There is some evidence that it has explanatory power over the determination of the regime path but it is not consistent across different specifications. Overall, our findings suggest that cross-market interdependencies, and not contagion, were central to the transmission of the initial subprime-mortgage market shock across the U.S. financial system.

The remainder of the paper is organised as follows. Section 2 describes the data, paying special attention to the ABX.HE indexes that we employ to track the U.S. subprime mortgage-backed market. Section 3 presents our econometric methodology. Section 4 outlines our model specification, reports and discusses our results, and presents a number of robustness checks. Finally, Section 5 contains our concluding remarks.

\section{Data}

\subsection{The ABX.HE indexes}

The exceptional growth of the subprime mortgage-backed securities sector during the early 2000s led to the creation of the ABX.HE indexes, standardised indexes that initially provided credibility,

\footnotetext{
${ }^{3}$ Variants of this type of model have previously been employed in the currency crisis literature by Peria (2002), Mandilaras and Bird (2010) and Brunetti, Scotti, Mariano, and Tan (2008), while Guo, Chen, and Huang (2011) apply a MS-VAR model to test for contagion between the market for credit default swaps (CDS), equity, real estate and energy markets.
} 
transparency and liquidity to this relatively new and innovative structured finance market. ${ }^{4}$ Produced by the Markit Group, the first index was launched on January 19, 2006 (ABX 06-1). Subsequently new indexes were introduced at six-monthly intervals, i.e., July 19, 2006 (ABX 06-2), January 19, 2007 (ABX 07-1) and July 19, 2007 (ABX 07-2) until the underlying asset market became so impaired that the fifth issue was postponed indefinitely and is now unlikely to take place. The reason for rolling the indexes in this fashion was to provide information on prevailing conditions in the subprime mortgage market but it also meant that the underlying asset quality could vary from one vintage to another.

Each index tracks twenty equally weighted, static U.S. portfolios of credit default swaps (CDS) backed by subprime mortgages, issued in the six-month period prior to the index launch date. Each index adopts a Collateralized Debt Obligation (CDO) structure with five distinct tranches, covering specifically rated reference obligations. The asset/tranche ratings (AAA, AA, A, BBB, and BBB-) are assigned in accordance with those issued by Moody's and Standard and Poor's (S\&P's) with the lower rating chosen when the two agencies differ in their assessment of credit quality. In order to be included in the index each residential mortgage-backed security (RMBS) must meet stringent requirements, such as deal size must be at least $\$ 500$ million, the weighted average Fair Isaac Corporation (FICO) score of the creditors backing the securities issued in the RMBS transaction may not be greater than 660 and at least four of the required tranches must be registered pursuant to the U.S. Securities Act of 1933. ${ }^{5}$ Each index is a synthetic CDO in which the ratings do not differentiate borrowers according to their risk profiles. Instead they simply distinguish the order in which investors bear losses and receive payments. The misconception that a AAA-rated ABX asset was equal to that of a AAA-rated corporate bond led many mandate-driven bodies, such as pension funds and universities, to invest heavily in these securities.

Fig. 1 plots ABX raw prices for each index from its issuance date until December 31, 2011. ${ }^{6}$

There is clearly a steep decline in prices in all four indexes over the sample period. As the subprime deals underlying the ABX 06-1 index were issued in the second half of 2005 the assets underlying this index would be of considerably better quality than those included in later issued indexes. ${ }^{7}$ It is clear that all assets in this index traded at or near par for all of 2006 before declining rapidly during 2007, a trend replicated in the other three indexes. However, the AAA-rated asset in the ABX 06-1 index does not reach the lows of later issued assets of equivalent credit rating, highlighting that the later issued indexes were of deteriorating quality (with an associated increase in risk) and consequently were hardest hit during the crisis. However, the AAA-rated assets of all indexes are clearly differentiated from the other tranches of any given vintage. The tranches rated below AAA all suffer huge losses and are hardly distinguishable by the sample end.

Given that our main focus is on measuring contagion emanating from this market, an important choice must be made between the subprime mortgage-backed assets. We choose to work with the returns (measured as the difference in the logarithm of each index) on AAA-rated assets as the relative size of this tranche swamped the other tranches in many of the underlying structured products. Also, as we can see from Fig. 1, the AAA-tranche was the most liquid tranche in each index and therefore provides a truer reflection of market conditions for this sector. We use two alternative series. Firstly, we include the longest available AAA-rated variable, namely that from the January 2006 index. Secondly we replicate the spliced index of Longstaff (2010), who constructs an on-the-run ABX index, by splicing the series together at each issuance date, i.e., July 19, 2006, January 19, 2007 and July 19, 2007. While it could be argued that the spliced series better reflects the prevailing conditions in the market, there are also some potential pitfalls associated with this approach. Dungey et al. (2013) argue that, given

\footnotetext{
4 Stanton and Wallace (2011) provide an excellent overview of the ABX indexes and raise concerns about what drives the prices of these indexes. However they remain the only publicly available data on subprime mortgage-backed assets and have been used to analyse the market by Fender and Scheicher (2008), Longstaff (2010), Dungey et al. (2013), among others.

5 In the U.S. an individual's credit risk is commonly measured by a FICO score. These scores range from 300 to 850 and are based on analysis of the individual's credit history. A mortgage issued to a borrower with a FICO score of 620 or less is classified as a subprime mortgage.

${ }^{6}$ Note that as each index was issued six months subsequent to the previous vintage the data are unbalanced.

7 Demyanyk and Van Hemert (2011) document a gradual, but persistent, decline in the quality of subprime loans from 2001 to 2007 .
} 

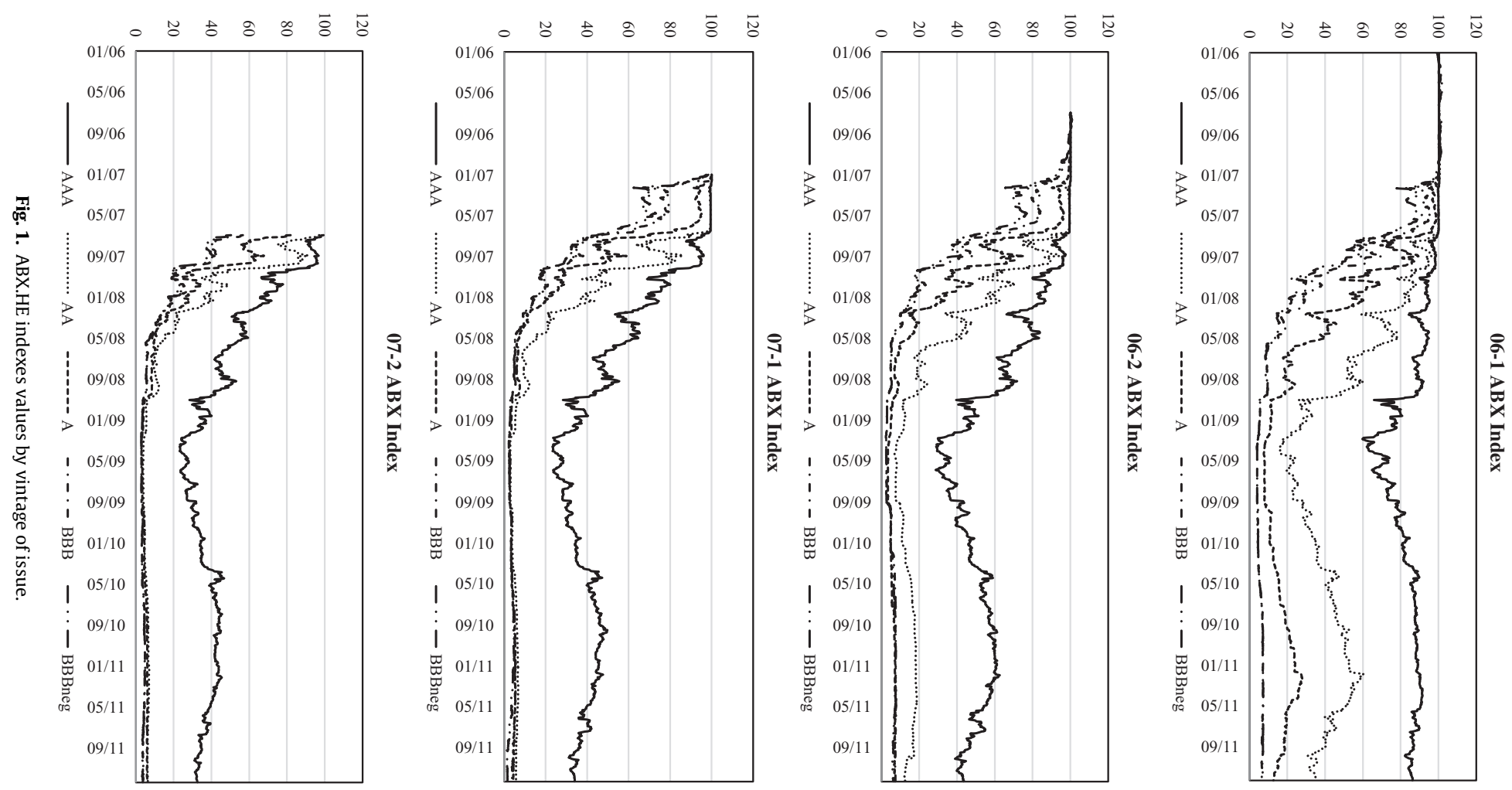




the differences in the underlying assets and their risk profiles, the various indexes are not suitable for splicing and should be treated as separate assets. Furthermore, as our definition of correlation-based contagion is "a statistically significant change in asset relationships between crisis and non-crisis periods", the changing composition of the spliced index could potentially obscure asset linkages over time and bias our conclusions. Using both series allows us to assess if differences between the traded and the spliced series are important in generating our results. The ABX data have been obtained from the Markit Group Ltd. and daily returns are used in the analysis. The sample period ranges from January 19, 2006, to December 31, 2011.

\subsection{Financial market variables}

To cover the various sectors of the U.S. financial system, and to compare our findings to those of Longstaff (2010), our empirical application includes variables from equity, corporate debt, U.S. Treasury, liquidity and volatility markets, as well as the subprime mortgage-backed market. Since we employ a range of model specifications and robustness checks, the following variables are all utilised at various points in the analysis. The U.S. equity market is represented by the returns on the S\&P 500 index and/or a sub-index of financial stocks. Conditions in the corporate debt market are measured by the changes in spreads of the rates on Aaa- and Baa-rated debt over the 10-year Treasury rate. Our Treasury market proxies attempt to capture both long- and short-term interest rate changes so we use the change in both the one- and 10-year Treasury rates. Financial market liquidity is captured by two variables, namely the change in the Libor-OIS spread and the change in the rate charged on 30day asset-backed commercial paper (ABCP). The former reflects conditions in the interbank market while the latter represents the market for short-term funding. The VIX index of implied volatility, computed from options on the S\&P 500, serves as our volatility market variable. The change in the VIX index reflects the changing expectations of future market uncertainty and is our chosen volatility proxy. Treasury and corporate yield data and the Libor-OIS spread have been obtained from the Federal Reserve Board while S\&P, the ABCP and VIX data have been obtained from the Bloomberg system. As with the $A B X$ indexes the financial market variables data range from January 19, 2006, to December 31, 2011.

Given the relatively short data sample available to us, we choose to work with daily data, rather than the weekly sampling employed by Longstaff (2010). The fast and furious nature of the changes during the crisis period is probably better captured by higher frequency data. Furthermore, the econometric methodology employed in this study (outlined below) is better able to distinguish between regimes with more available data points.

\subsection{Summary statistics}

Table 1 reports summary statistics for daily returns of the ABX indexes and changes to the financial variables under analysis over the sample period.

Over the whole sample, the mean returns on each of the ABX assets are negative and decreasing in credit quality. Consistent with Fig. 1, losses on the lower-rated tranches are much more pronounced than those for their higher-rated counterparts. All tranches with a credit rating lower than AAA suffer returns that are at least three times more negative than the most senior, AAA-rated, asset. In general, the volatility of the asset returns are inversely related to the credit rating of the asset, though the BBBasset of the ABX 06-1 index violates this trend. Volatility increases more than $100 \%$ for the traded 06-1 and $37 \%$ for the spliced index as the ratings decline from AAA to BBB-. Comparing the traded index to the spliced index, the returns are always more negative and usually more volatile on the spliced index. This is due to the fact that the spliced index is composed of different asset vintages and is based on the ABX 07-2 index for almost three quarters of the sample. This index, whose underlying deals were struck when property prices were already in decline and subprime mortgages were quickly falling into negative equity, suffered the sharpest decline of all the subprime mortgage-backed assets and greatly influences the behaviour of the spliced index. All returns are negatively skewed, consistent with the realisation of more adverse shocks than incidences of good news. Finally, all assets display significant leptokurtosis, indicating the presence of fat tails in their distributions. This may signal that the asset 
Table 1

Summary statistics.

\begin{tabular}{llllllr}
\hline Data set & Rating & Obs. & Mean & Std. dev. & Skewness & Kurtosis \\
\hline ABX 06-1 index & AAA & 1552 & -0.006 & 0.798 & -1.065 & 23.731 \\
& AA & 1552 & -0.046 & 1.860 & -0.201 & 16.755 \\
& A & 1552 & -0.130 & 1.931 & -0.776 & 13.792 \\
& BBB & 1552 & -0.182 & 1.958 & -2.732 & 24.219 \\
& BBB- & 1552 & -0.176 & 1.788 & -2.272 & 20.626 \\
Spliced ABX index & AAA & 1552 & -0.057 & 1.607 & -0.086 & 12.839 \\
& AA & 1552 & -0.187 & 1.942 & -2.393 & 27.827 \\
& A & 1552 & -0.199 & 1.842 & -1.230 & 9.748 \\
& BBB & 1552 & -0.227 & 2.217 & -1.122 & 8.126 \\
& BBB- & 1552 & -0.224 & 2.211 & -1.067 & 6.299 \\
& S\&P 500 & 1552 & 0.0051 & 1.484 & -0.468 & 6.518 \\
& S\&P financials & 1552 & -0.0398 & 2.745 & -0.081 & 8.636 \\
& One-year T-bill & 1552 & -0.0027 & 0.048 & -0.154 & 25.368 \\
& 10-year T-bond & 1552 & -0.0018 & 0.0679 & -0.214 & 3.061 \\
& Aaa spread & 1552 & 0.0005 & 0.089 & -0.093 & 4.445 \\
& Baa spread & 1552 & 0.00096 & 0.037 & 2.079 & 18.206 \\
& VIX & 1552 & 0.0002 & 2.146 & 0.653 & 13.138 \\
& ABCP & 1552 & -0.0028 & 0.143 & 1.544 & 73.185 \\
& Libor-OIS & 1552 & 0.00001 & 0.038 & 0.220 & 35.158 \\
\hline
\end{tabular}

Notes: This table reports summary statistics for the daily percentage changes for the indicated ABX indexes and financial market variables over the entire sample period. The sample consists of daily data from January 20, 2006 to December 31, 2011. Obs. denotes number of observations; Std. dev. denotes standard deviation.

returns are better modelled as a mixture of distributions or by a regime-switching framework. The financial variables also highlight some interesting features of the markets during this period. Firstly, the financial sector of the equity market generates negative mean returns, while the return on the market as a whole is slightly positive. Furthermore, financial stock returns exhibit far more volatility than the market index. The mean returns on both Treasury instruments are mildly negative over the sample, reflecting the series of interest rate cuts introduced to encourage investment during the recessionary period. Changes in corporate spreads average out at close to zero, though there is higher volatility associated with the Aaa-rated sector, possibly due to the fact that these remained relatively more liquid during the crisis. Likewise changes to the VIX, the ABCP rate, and the Libor-OIS spread are negligible, on average, over the sample. Again all assets display evidence of being subjected to large shocks of either sign (kurtosis) and significant asymmetries (skewness) over the time period.

\section{The econometric methodology}

Longstaff (2010) estimates a VAR model for each phase of the crisis and compares the relationships between variables across these different time periods. The main advantage of the VAR framework is that it is flexible enough to allow a relatively large number of assets to be considered simultaneously. However, it also has a number of limitations. Firstly the crisis dates must be imposed exogenously. This is often a contentious issue in assigning both the start and end dates, e.g., in recent studies of the subprime crisis, Longstaff (2010) uses the calendar year of 2007 as the crisis period, while many others use a later start date of July or August of that year (see Dungey, Fry, González-Hermosillo, Martin, \& Tang, 2009; Hatemi-J \& Roca, 2011; among others). Secondly, this type of approach treats all days within the defined crisis period equally, even though there will most likely be many days without significant news for the financial markets. Thirdly, a model that is capable of modelling the heteroskedasticity generated by regime shifts is likely to be more efficient and provide a better characterisation of financial crises than a standard VAR approach. Hamilton $(1989,1990)$ popularised the use of Markov-switching models in economic studies. Their application within the contagion literature has also become more common (Flavin \& Panopoulou, 2010; Gravelle, Kichian, \& Morley, 2006; Jeanne \& Masson, 2000; among others). 
We wish to retain the flexibility of the VAR model while overcoming the limitations outlined above. Thus, the Markov-switching VAR (MS-VAR) appears to be ideally suited to our needs. It allows the crisis dates to be selected endogenously, accounts for no-news days within the turbulent period and models the heteroskedasticity of financial assets within the regime-switching structure.

We employ a two-state MS-VAR, with our two discrete states denoted as $s_{1}$ and $s_{2}$. $s_{1}$ represents a low-volatility, "non-crisis" regime while $s_{2}$ represents a high-volatility, "crisis" regime. A two-regime model is chosen due to the relatively short length of our data and it provides a tractable framework within which to apply our definition of correlation-based contagion, i.e., a significant increase in crossmarket linkages following a shock in one market, and to test for its presence. Our model takes the following form:

$$
y_{i, t}=\alpha\left(s_{t}\right)+\sum_{k=1}^{K} \beta_{k}\left(s_{t}\right) y_{i, t-k}+\epsilon_{i, t}^{s t}, \quad s_{t} \in\{1,2\}, \quad \epsilon_{i, t}^{s t} \sim \text { i.i.d.N }\left(0, \sigma_{s}^{2}\right),
$$

in which $y_{i, t}$ is an $n$ dimensional time series vector of dependent variables, $\alpha$ is a matrix of state dependent intercepts, $\beta_{1}, \ldots, \beta_{k}$ are matrices of the state dependent autoregressive coefficients and capture the relationships between our financial variables, and $\epsilon_{i, t}^{s t}$ is a state dependent noise vector, which has a zero mean and constant variance within each regime. $s_{t}$ is an unobserved random variable that signals the switch from regime to another. Since the true regime cannot be observed, we must specify the paths by which the regimes transit from one to another. We assume $s_{t}$ follows a first-order Markov process in which the current regime, $s_{t}$ relies only on the regime one period in the past, $s_{t-1}$.

Early Markov-switching regime models imposed a fixed transition probability (FTP) on the movement between states, a restriction which was relaxed by Filardo (1994). He proposed a methodology which allows the transition probabilities to vary over time and be modelled as functions of chosen information variables, i.e., a variable that triggers the switch in regime. This time-varying transition probability (TVTP) specification nests the FTP model and allows us to test if the conditioning variables have explanatory power over the regime switches. In our application, this provides a natural way to test for the type of contagion proposed by Masson (1999a, 1999b). However, the information variable must be selected carefully. Filardo (1998) details the conditions that this variable must satisfy. The information variable must, in general, be uncorrelated with the contemporaneous regime and thus consequently, most empirical applications of the TVTP model select lagged, pre-determined, variables upon which to condition the regime path. Thus the regimes paths evolve according to a first order Markov-chain and are directly affected by the information variable $z_{t-l}$ :

$$
\begin{aligned}
& p\left[s_{t}=1 \mid s_{t-1}=1\right]=p_{11}\left(z_{t-1}\right), \\
& p\left[s_{t}=2 \mid s_{t-1}=2\right]=p_{22}\left(z_{t-1}\right), \\
& p\left[s_{t}=2 \mid s_{t-1}=1\right]=p_{12}\left(z_{t-1}\right), \\
& p\left[s_{t}=1 \mid s_{t-1}=2\right]=p_{21}\left(z_{t-1}\right),
\end{aligned}
$$

in which $p_{i j}$ denotes the probability that the system is in state $i$ at time $t-1$ and in state $j$ at time $t$. In common with much of the applied literature, we model the transition probabilities as a logistical functional form:

$$
\begin{aligned}
& p_{11}\left(z_{t-l}\right)=\frac{\exp \left(\theta_{0}+\sum_{l=1}^{L} \theta_{l} z_{t-l}\right)}{1+\exp \left(\theta_{0}+\sum_{l=1}^{L} \theta_{l} z_{t-l}\right)}, \\
& p_{22}\left(z_{t-l}\right)=\frac{\exp \left(\gamma_{0}+\sum_{l=1}^{L} \gamma_{l} z_{t-l}\right)}{1+\exp \left(\gamma_{0}+\sum_{l=1}^{L} \gamma_{l} z_{t-l}\right)} .
\end{aligned}
$$

The FTP alternative is nested within the TVTP model. In particular, for $L=1$, if the $\theta_{1}$ and $\gamma_{1}$ parameters are jointly zero, then the TVTP model collapses to the FTP model. The model is estimated using the Expectation Maximization (EM) algorithm, as described in Hamilton (1990). 


\section{Estimated models and results}

\subsection{Model specification}

As our model is highly nonlinear, we aim for a parsimonious representation of the U.S. financial system. Our initial analysis is performed on a six variable system with each variable selected to represent a particular sector of the financial system. The subprime asset-backed securities market is represented by the highest-rated and longest-traded ABX tranche available, i.e., the AAA-rated tranche of the ABX 06-1 index. We also employ, in a separately estimated model, the spliced index. We feel that the continuously-traded asset is more suited to tests of contagion but using both allows us to assess if the choice of traded or spliced data is important in explaining the results. The S\&P 500 index and the change in the Aaa-rated corporate spread over Treasuries are taken to represent the equity and corporate debt markets respectively. Conditions in the market for U.S. Treasuries are captured by the change in the one-year Treasury rate, while the general financial market environment is proxied by a liquidity variable, the change in the Libor-OIS spread, and the change in the VIX index.

Given the large number of parameters to be estimated in our six variable system, we are mindful of not including too many lags in the MS-VAR model. We began our analysis with four lags $(K=4$ in Eq. (1)) but due to the non-significance of any of the fourth lags, we reduced the dimensionality of the system to $K=3$. This procedure was repeated until finally settling on two lags, $K=2$.

Finally, we select the information variable that potentially influences the regime paths. As we are primarily interested in the effect of the subprime-mortgage backed sector on the broader financial system, we turn to our ABX assets to select this trigger variable. Ideally, we would like an exogenous variable. Since we include the AAA-rated asset as an endogenous variable in the MS-VAR, we prefer to select a variable from outside of the system. We therefore turn to the returns on the AA-rated asset of the ABX 06-1 index (or the spliced index, when appropriate). However, the AA-rated asset cannot really be thought of as being truly uncorrelated with the state of the system so, in our application, we use the first lag of this variable, i.e., we set $L=1$ in Eq. (3). Thus, our TVTP MS-VAR analysis includes the AAA-rated asset within the VAR model, with regime changes dependent upon the lagged behaviour of the AA-rated asset. ${ }^{8}$

\subsection{Discussion of results}

Initially, we focus on the ability of the information variable to predict the regime switches in our model. In particular, we test the hypothesis that the lagged return on the AA-rated asset contains no information relevant to the determination of the regime which, if true, would imply that there is no evidence of contagion from the subprime mortgage-backed market. We perform a likelihood ratio (LR) test in which our null hypothesis is that $\theta_{1}=\gamma_{1}=0$.

Though the signs of the coefficients on the information variable make intuitive sense with the positive $\theta_{1}$ and negative $\gamma_{1}$ implying that good (bad) news in the ABX market increases the probability of being in the non-crisis (crisis) regime, these coefficients are not significantly different from zero. Consequently, we fail to reject the null hypothesis that $\theta_{1}$ and $\gamma_{1}$ are jointly zero. This implies that the lagged return on the ABX asset is not informative in predicting the regime switches over the period and therefore provides no evidence that contagion from this market was an important factor leading to the widespread financial market turmoil experienced.

Table 2 also presents the expected values and volatility of all assets. We classify the regimes by analysing the volatility of the variables in each state. There is no ambiguity as the volatility of all assets increases substantially in state 2 , allowing us to easily identify this as the crisis period. Table 2 also shows that, as we move from the non-crisis to the crisis regime, the sign of the constant terms changes for every asset. The non-crisis period is characterised by statistically significant positive changes to the prices of the subprime mortgage-backed asset and equity, while the Libor-OIS spread is on average

\footnotetext{
8 Our results are not dependent on the choice of information variable. We check their robustness by selecting other tranches of the ABX index and it does not alter our conclusions.
} 
Table 2

Model estimates for transition probabilities, expected values and standard deviations: analysis using traded ABX 06-1 index.

\begin{tabular}{llll}
\hline \multicolumn{2}{l}{ Panel A: transition probabilities } & & \\
\hline$\theta_{0}$ & $2.338^{* * *}$ & $\theta_{1}$ & 0.136 \\
$\gamma_{0}$ & $1.288^{* * *}$ & $\gamma_{1}$ & -0.037 \\
$H_{0}:$ & $\theta_{1}=\gamma_{1}=0$ & LR test stat. & 2.87
\end{tabular}

Panel B: expected returns and standard deviations

\begin{tabular}{|c|c|c|c|c|}
\hline & \multicolumn{2}{|c|}{ Non-crisis regime } & \multicolumn{2}{|c|}{ Crisis regime } \\
\hline & $\alpha$ & $\sigma$ & $\alpha$ & $\sigma$ \\
\hline ABX AAA-rated asset & $\begin{array}{l}0.0341 \\
\left(3.30^{* * *}\right)\end{array}$ & $\begin{array}{l}0.0872 \\
\left(31.21^{* * *}\right)\end{array}$ & $\begin{array}{l}-0.0696 \\
(-0.80)\end{array}$ & $\begin{array}{l}1.6319 \\
\left(15.97^{* * *}\right)\end{array}$ \\
\hline S\&P 500 index & $\begin{array}{l}0.0780 \\
\left(2.37^{* *}\right)\end{array}$ & $\begin{array}{l}0.8385 \\
\left(25.39^{* * *}\right)\end{array}$ & $\begin{array}{l}-0.1995 \\
(-1.29)\end{array}$ & $\begin{array}{l}5.0240 \\
\left(11.36^{* * *}\right)\end{array}$ \\
\hline Aaa corporate spread & $\begin{array}{l}-0.0025 \\
(-1.26)\end{array}$ & $\begin{array}{l}0.0036 \\
\left(27.31^{* * *}\right)\end{array}$ & $\begin{array}{l}0.0106 \\
(1.51)\end{array}$ & $\begin{array}{l}0.0114 \\
\left(13.77^{* * *}\right)\end{array}$ \\
\hline One-year $T$-bill & $\begin{array}{l}0.0005 \\
(0.71)\end{array}$ & $\begin{array}{l}0.0004 \\
\left(27.70^{* * *}\right)\end{array}$ & $\begin{array}{l}-0.0111 \\
\left(-2.14^{* *}\right)\end{array}$ & $\begin{array}{l}0.0062 \\
\left(17.14^{* * *}\right)\end{array}$ \\
\hline Libor-OIS spread & $\begin{array}{l}-0.0005 \\
\left(-2.02^{* *}\right)\end{array}$ & $\begin{array}{l}0.0001 \\
\left(26.65^{* * *}\right)\end{array}$ & $\begin{array}{l}0.0027 \\
(0.55)\end{array}$ & $\begin{array}{l}0.0045 \\
\left(18.67^{* * *}\right)\end{array}$ \\
\hline VIX index & $\begin{array}{l}-0.0722 \\
\left(-1.65^{*}\right)\end{array}$ & $\begin{array}{l}1.5294 \\
\left(27.47^{* * *}\right)\end{array}$ & $\begin{array}{l}0.1706 \\
(0.71)\end{array}$ & $\begin{array}{l}10.8485 \\
\left(12.68^{* * *}\right)\end{array}$ \\
\hline
\end{tabular}

Notes: Panel A reports the coefficients on the transition probabilities (Eq. (3)) and a likelihood ratio(LR) test on the null hypothesis that the information variable (lagged return on the AA-rated 06-1 asset) has no explanatory power over the regime path. Panel B reports the regime-specific constant terms and variances from Eq. (1). T-statistics are reported in parenthesis. ${ }^{* * *},{ }^{* *},{ }^{*}$ denote significance at the $1 \%, 5 \%$ and $10 \%$ levels, respectively.

decreasing. Though not statistically significant at conventional levels, this period is typified by negative changes to the Aaa-rated corporate spread and the VIX index, while daily changes in the one-year Treasury rate are approximately zero. In contrast, the only statistically significant coefficient in the crisis period suggests a declining rate on the one-year Treasury bill as the Federal Reserve aggressively cut interest rates. The other estimates suggest negative equity and ABX returns, increasing corporate debt yields and short-term funding costs as well as greater uncertainty about the future financial environment were all features of the turbulent period.

Table 3 presents the regime-specific correlations between each pair of assets. We report these simply to illustrate the changes in asset co-movements between regimes and they should not be interpreted as evidence of contagion. The lower triangle of Table 3 contains those correlations which pertain to the non-crisis period with the corresponding numbers for the crisis period reported on the upper triangle. Focussing initially on the ABX asset, we see that in both regimes it has positive comovement with changes in the equity market and with the one-year Treasury rate but is negatively related to changes in the Aaa corporate spread, the Libor-OIS spread and the VIX index. Interestingly the magnitude of its correlation with each of the other assets intensifies during the crisis regime. This

Table 3

Regime-specific correlations: analysis using traded 06-1 index.

\begin{tabular}{lcccccc}
\hline & ABX & S\&P 500 & Aaa spread & One-year T-bill & Libor-OIS & VIX \\
\hline ABX & 1 & 0.383 & -0.270 & 0.156 & -0.023 & -0.329 \\
S\&P 500 & 0.366 & 1 & -0.315 & 0.320 & -0.146 & -0.830 \\
Aaa Spread & -0.200 & -0.378 & 1 & -0.401 & -0.031 & 0.241 \\
One-year T-bill & 0.060 & 0.071 & -0.215 & 1 & -0.135 & -0.288 \\
Libor-OIS & -0.013 & 0.016 & -0.050 & -0.138 & 1 & 0.129 \\
VIX & -0.312 & -0.833 & 0.329 & -0.061 & -0.014 & 1 \\
\hline
\end{tabular}

Notes: This table reports the asset correlations generated by our TVTP MS-VAR model. Correlations for the non-crisis period are reported in the lower triangle of the table, while the crisis period correlations are presented in the upper triangle. 


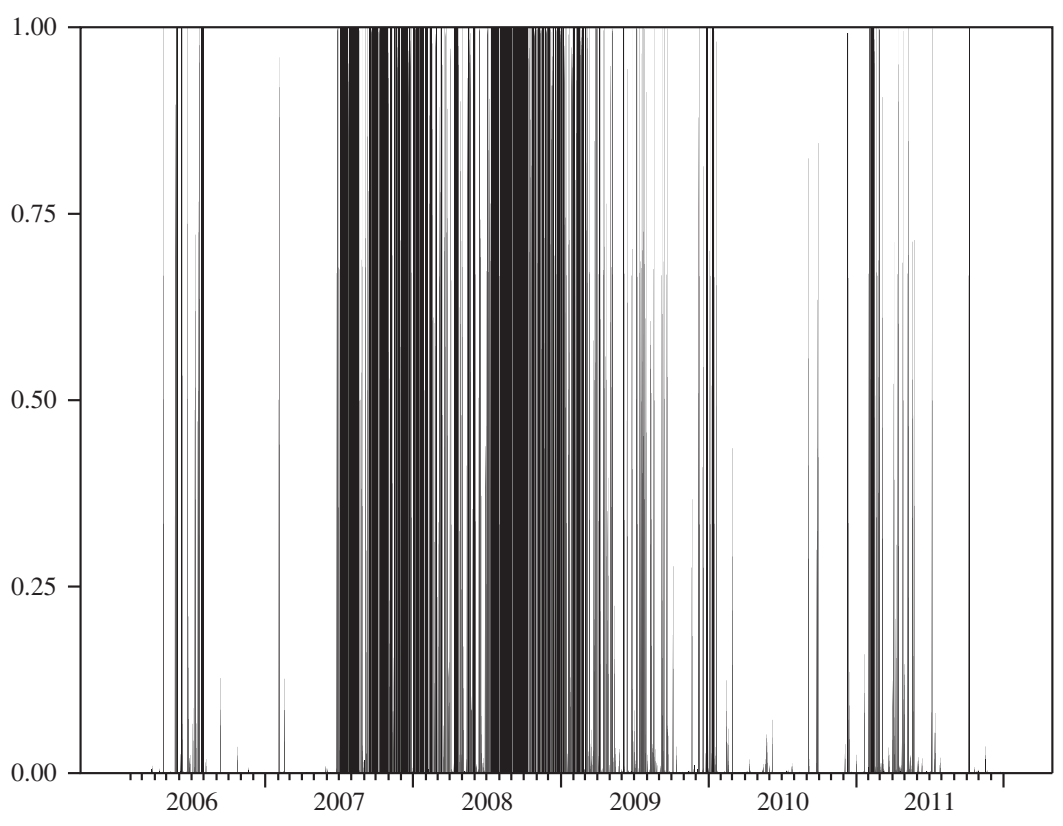

Fig. 2. Smoothed probability of a crisis regime: analysis using traded ABX 06-1 index.

pattern is generally true for the other assets in the system but there are some exceptions. The increases in the absolute value of the pairwise correlations are a feature of high-volatility crisis periods (Forbes \& Rigobon, 2002) and while it may suggest a change in cross-market relationships, we require further analysis before we can conclude if this constitutes contagion or not.

To undertake this analysis, we first plot the smoothed probabilities of the system being in a crisis regime. We calculate these probabilities as follows:

$$
P\left(S_{t}=i \mid F_{T} ; \theta\right), \quad i=1,2,
$$

in which $F_{T}$ denotes the collection of all observed variables up to and including time $T$, i.e., all information in the sample and $\theta$ is the vector of parameters $\left(\alpha(s), \beta_{k}(s), \sigma_{s}^{2}, p_{11}, p_{22}, p_{12}, p_{21}\right)$. Smoothed estimates are then computed via the backward recursion algorithm as presented by Kim (1994) and Hamilton (1994).

Fig. 2 shows the smoothed probability of the system being in a crisis regime and suggests that the watershed of regimes occurred about July 2007. This starting point coincides with that employed by Dungey et al. (2009) and Hatemi-J and Roca (2011) but contrasts with the earlier start date of Longstaff (2010). It depicts how the early part of 2007 was predominantly a tranquil time in the financial markets and therefore highlights the danger of employing this calendar year as the "subprime crisis" period, since it is a mixture of two different states of the world. Therefore treating it as a single episode masks potentially important changes occurring between regimes. The crisis persists for roughly two years before the non-crisis period re-establishes itself as the more likely regime in early-2009. Another interesting feature of Fig. 2 is that even within the crisis period, there are a number of days when markets returned to a state of tranquillity, especially during the second quarter of 2008 . This was possibly due to little news or thin trading on those days, so it is important not to include such days in our crisis sample since they may dilute the true intensity of the shock transmission during the turbulent episode.

Finally, we address the main issue; do the results of our analysis produce evidence of contagious effects transmitting the crisis across financial markets or can interdependencies between these sectors account for the widespread financial turmoil? The former is characterised by parameter instability 
Table 4

Tests for contagion: analysis using traded ABX 06-1 index.

\begin{tabular}{lllllll}
\hline Contagion from & ABX & S\&P 500 & Aaa spread & One-year T-bill & Libor-OIS & VIX \\
\hline To & & & & & & 0.93 \\
ABX & - & 0.21 & 0.46 & 0.85 & 0.26 & 0.36 \\
S\&P 500 & 0.34 & - & 0.23 & 0.51 & $0.03^{* *}$ & $0.04^{* *}$ \\
Aaa spread & 0.78 & 0.77 & - & 0.76 & 0.96 & 0.45 \\
One-year T-bill & 0.85 & 0.77 & 0.95 & - & - & 0.42 \\
Libor-OIS & 0.89 & 0.68 & 0.91 & 0.22 & $0.10^{*}$ & - \\
VIX & 0.52 & 0.22 & 0.22 & 0.92 & \\
\hline
\end{tabular}

Notes: This table reports the $p$-values of our Likelihood ratio (LR) tests for contagion between each pair of assets. Contagion is defined as a statistically significant change in asset relationships between non-crisis and crisis periods, so our test is based on the null hypothesis of "No Contagion", i.e., $\beta_{i j, k}(s=1)=\beta_{i j, k}(s=2)$, where $i$ and $j$ represent the assets under consideration, $k$ the lag and $i \neq j$. Failure to reject the null hypothesis implies that asset relationships are stable across regimes. ${ }^{* * *},{ }^{* *},{ }^{*}$ denote significance at the $1 \%, 5 \%$ and $10 \%$ levels, respectively.

between regimes whereas the latter would yield stable relationships. Table 4 presents the p-values from a likelihood ratio test where the null hypothesis is that the VAR coefficients do not change as we move between regimes, i.e., $\beta_{i j, k}(s=1)=\beta_{i j, k}(s=2)$, where $i$ and $j$ represent the assets under consideration, $k$ the lag and $i \neq j$.

We first concentrate on the transmission channels from the AAA-rated subprime mortgage-backed asset to the other sectors of the financial system. In contrast to Longstaff (2010), we find no statistical evidence of a change in the relationship between the ABX asset and any of the other assets under consideration during the crisis period. Hence we conclude against the presence of contagion. Similarly, there is no evidence of contagion from the other assets to the ABX asset. Thus, it appears to be interdependence between markets that propagated the initial shock to the subprime mortgage-backed sector across the U.S. financial system. The responses of other markets to this shock could have been anticipated if the degree of cross-market integration or interdependence had been properly recognised. In a study of international stock markets, Brière, Chapelle, and Szafarz (2012) reach a similar conclusion regarding the spread of crises. The international transmission of shocks is attributed to globalisation rather than to contagion.

We continue to analyse the remainder of the system and find limited evidence of contagion. In fact, the only evidence produced that is consistent with different relationships between crisis and non-crisis periods relates to the liquidity variable, Libor-OIS, and the VIX. Our results suggest that there was contagion from the Libor-OIS spread to both the corporate debt market and the VIX index. Furthermore the relationship between the VIX and the S\&P also intensified during the crisis period. All other relationships remain stable between regimes.

At first, the lack of evidence of contagion in the U.S. financial system may appear confusing given the widespread turmoil experienced. The majority of pairwise relationships remained stable during this transition, implying that ultimately the negative returns, higher spreads, reduced liquidity and increased uncertainty were due to the strong interdependence of the various sectors of the financial system rather than to contagion. Given the relationships that existed between the ABX asset and the other variables during "normal" market conditions, then if one had correctly anticipated the magnitude of the downturn in the asset-backed market, one should also have expected the changes to the other assets. The only evidence of excessive shock transmission stems from the liquidity variable to the corporate debt and volatility markets and from the VIX to the equity market. In these instances, the responses in the recipient markets to liquidity and volatility shocks were greater than could have been anticipated based on non-crisis relationships. These excessive responses provide us with limited evidence of contagion.

We undertake a number of robustness checks. Firstly, we change the composition of the six-variable vector, $y_{t}$. In particular, we replace the S\&P 500 index with the S\&P subindex of financial stocks. In another application, we change our liquidity variable to the change in the ABCP rate. We analyse many different combinations - though not an exhaustive set of combinations - and our conclusions do not change. There is no evidence of contagion from (or to) the subprime mortgage-backed market. We 


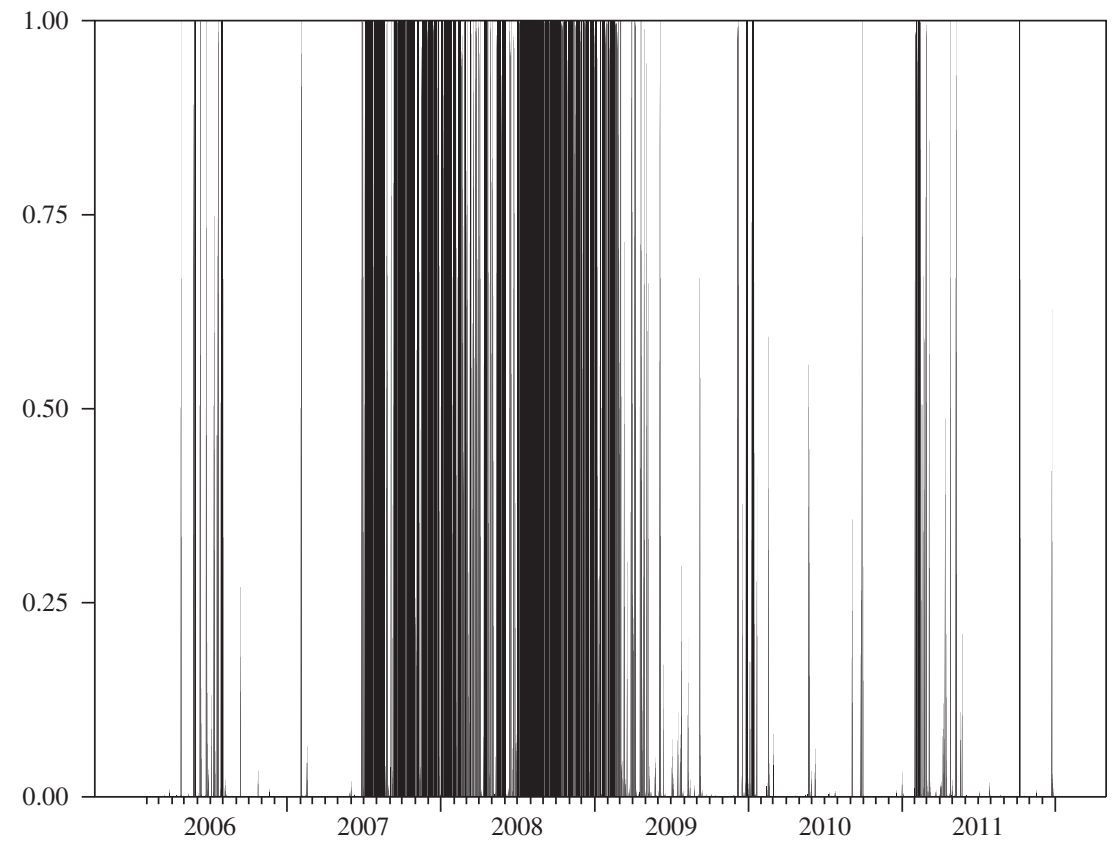

Fig. 3. Smoothed probability of a crisis regime: analysis using spliced ABX index.

continue to see evidence of contagion from the liquidity variable though the evidence from the ABCP rate is less compelling than from the Libor-OIS spread. ${ }^{9}$ We also investigate the role of the spliced ABX index and finally look at the evidence from more parsimonious models. These results are discussed in the following sections.

\subsection{Robustness checks with the spliced index}

Given the disparity between our results and those of Longstaff (2010), we repeat our analysis using the spliced series, instead of the traded asset, as our proxy for the subprime mortgage asset-backed market. We wish to investigate if using this series produces more evidence of contagion since the composition of the reference assets change on each splicing date and, consequently, differ between crisis and non-crisis periods. As argued earlier, the quality of the assets underlying the index deteriorated across vintage of issue so, a priori, we cannot rule out that the splicing together of these different vintages may artificially induce changes in the relationships among variables between different regimes.

We re-estimate the model and our results are contained in Fig. 3 and Tables 5-7. Given the similarity of results, we briefly sketch our main findings here, paying attention to areas of difference.

The most important difference is the role of the information variable in determining the regime path. Unlike the traded asset, the return on the spliced AA-rated ABX asset exerts a statistically significant influence on the transition probabilities. Again the coefficients signs are intuitively correct and we reject the null hypothesis that $\theta_{1}$ and $\gamma_{1}$ are jointly zero. In fact, only $\theta_{1}$ is individually significant, suggesting that the subprime mortgage-backed market influenced the switch to the crisis but not the subsequent exit from the turmoil. The role of the ABX asset return in the determination of the regime switch to the high-volatility, crisis state is consistent with the definition of contagion proposed by Masson (1999a, 1999b). This finding may be attributed to the declining quality of the

${ }^{9}$ To conserve space, we do not report these results but they are available from the authors. 
Table 5

Model estimates for transition probabilities, expected values and standard deviations: analysis using spliced ABX index.

\begin{tabular}{|c|c|c|c|}
\hline \multicolumn{4}{|c|}{ Panel A: transition probabilities } \\
\hline$\theta_{0}$ & $2.624^{* * *}$ & $\theta_{1}$ & $0.266^{* * *}$ \\
\hline$\gamma_{0}$ & $1.415^{* * *}$ & $\gamma_{1}$ & -0.049 \\
\hline$H_{0}:$ & $\theta_{1}=\gamma_{1}=0$ & LR test stat. & $9.80^{* * * *}$ \\
\hline
\end{tabular}

Panel B: expected returns and standard deviations

\begin{tabular}{|c|c|c|c|c|}
\hline & \multicolumn{2}{|c|}{ Non-crisis regime } & \multicolumn{2}{|c|}{ Crisis regime } \\
\hline & $\alpha$ & $\sigma$ & $\alpha$ & $\sigma$ \\
\hline ABX AAA-rated asset & $\begin{array}{l}0.0296 \\
(1.05)\end{array}$ & $\begin{array}{l}0.6776 \\
\left(30.54^{* * *}\right)\end{array}$ & $\begin{array}{l}-0.1990 \\
(-1.21)\end{array}$ & $\begin{array}{l}6.5814 \\
\left(15.25^{* * *}\right)\end{array}$ \\
\hline S\&P 500 index & $\begin{array}{l}0.0923 \\
\left(2.80^{* * *}\right)\end{array}$ & $\begin{array}{l}0.8868 \\
\left(26.69^{* * *}\right)\end{array}$ & $\begin{array}{l}-0.2451 \\
(-1.45)\end{array}$ & $\begin{array}{l}5.1512 \\
\left(11.25^{* * *}\right)\end{array}$ \\
\hline Aaa corporate spread & $\begin{array}{l}-0.0028 \\
(-1.34)\end{array}$ & $\begin{array}{l}0.0038 \\
\left(27.01^{* * *}\right)\end{array}$ & $\begin{array}{l}0.0125 \\
\left(1.66^{*}\right)\end{array}$ & $\begin{array}{l}0.0113 \\
\left(13.11^{* * *}\right)\end{array}$ \\
\hline One-year $T$-bill & $\begin{array}{l}0.0003 \\
(0.48)\end{array}$ & $\begin{array}{l}0.0004 \\
\left(27.61^{* * *}\right)\end{array}$ & $\begin{array}{l}-0.0111 \\
\left(-1.95^{*}\right)\end{array}$ & $\begin{array}{l}0.0067 \\
\left(15.74^{* * *}\right)\end{array}$ \\
\hline Libor-OIS spread & $\begin{array}{l}-0.0006 \\
\left(-2.64^{* * *}\right)\end{array}$ & $\begin{array}{l}0.0001 \\
\left(27.02^{* * *}\right)\end{array}$ & $\begin{array}{l}0.0035 \\
(0.66)\end{array}$ & $\begin{array}{l}0.0048 \\
\left(17.81^{* * *}\right)\end{array}$ \\
\hline VIX Index & $\begin{array}{l}-0.0826 \\
\left(-1.91^{*}\right)\end{array}$ & $\begin{array}{l}1.5888 \\
\left(28.95^{* * *}\right)\end{array}$ & $\begin{array}{l}0.1862 \\
(0.71)\end{array}$ & $\begin{array}{l}11.3008 \\
\left(12.02^{* * *}\right)\end{array}$ \\
\hline
\end{tabular}

Notes: Panel A reports the coefficients on the transition probabilities (Eq. (3)) and a likelihood ratio(LR) test on the null hypothesis that the information variable (the lagged return on the AA-rated spliced asset) has no explanatory power over the regime path. Panel B reports the regime-specific constant terms and variances from Eq. (1). T-statistics are reported in parenthesis. ${ }^{* * *}$, ${ }^{* *}$, * denote significance at the $1 \%, 5 \%$ and $10 \%$ levels, respectively.

Table 6

Regime-specific correlations: analysis using spliced $\mathrm{ABX}$ index.

\begin{tabular}{lllllll}
\hline & ABX & S\&P 500 & Aaa spread & One-year T-bill & Libor-OIS & VIX \\
\hline ABX & 1 & 0.443 & -0.254 & 0.204 & -0.018 & -0.419 \\
S\&P 500 & 0.324 & 1 & -0.328 & 0.325 & -0.148 & -0.828 \\
Aaa Spread & -0.175 & -0.356 & 1 & -0.412 & -0.029 & 0.244 \\
One-year T-bill & 0.080 & 0.063 & -0.228 & 1 & -0.136 & -0.291 \\
Libor-OIS & -0.040 & 0.004 & -0.046 & -0.126 & 1 & 0.131 \\
VIX & -0.253 & -0.836 & 0.319 & -0.056 & -0.004 & 1 \\
\hline
\end{tabular}

Notes: This table reports the asset correlations generated by our TVTP MS-VAR model, using the spliced AAA-rated ABX asset as our proxy for the subprime mortgage-backed market. Correlations for the non-crisis period are reported in the lower triangle of the table, while the crisis period correlations are presented in the upper triangle.

Table 7

Tests for contagion: analysis using spliced $\mathrm{ABX}$ index.

\begin{tabular}{lllllll}
\hline Contagion from & ABX & S\&P 500 & Aaa spread & One-year T-bill & Libor-OIS & VIX \\
\hline To & & & & & & 0.69 \\
ABX & - & 0.20 & 0.60 & 0.57 & 0.23 & 0.19 \\
S\&P 500 & 0.57 & - & 0.13 & 0.55 & $0.05^{* *}$ & 0.51 \\
Aaa spread & 0.41 & 0.40 & - & 0.52 & 0.66 & 0.48 \\
One-year T-bill & 0.62 & 0.71 & 0.98 & - & - & 0.37 \\
Libor-OIS & 0.44 & 0.60 & 0.90 & 0.30 & $0.06^{*}$ & - \\
VIX & 0.45 & 0.15 & 0.14 & 0.87 & \\
\hline
\end{tabular}

Notes: Here we use the spliced AAA-rated ABX asset to represent the subprime mortgage-backed market. This table reports the $p$-values of our Likelihood ratio (LR) tests for contagion between each pair of assets. Contagion is defined as a statistically significant change in asset relationships between non-crisis and crisis periods, so our test is based on the null hypothesis of "No Contagion", i.e., $\beta_{i j, k}(s=1)=\beta_{i j, k}(s=2)$, where $i$ and $j$ represent the assets under consideration, $k$ the lag and $i \neq j$. Failure to reject the null hypothesis implies that asset relationships are stable across regimes. ${ }^{* * *},{ }^{* *},{ }^{*}$ denote significance at the $1 \%, 5 \%$ and $10 \%$ levels, respectively. 
Table 8

Further tests of the role of the spliced index in explaining the regime path.

\begin{tabular}{ll}
\hline Panel A: Six-variable models with different samples & \\
Full sample & 0.25 \\
Start date: July 2006 & 0.55 \\
Start date: January 2007 & 0.02 \\
Start date: July 2007 & 0.01 \\
Panel B: Lower dimension models (full sample) & \\
Stock market model & 0.31 \\
Corporate debt market model & 0.36 \\
Treasury market model & 0.18 \\
Liquidity market model & 0.01 \\
Volatility market model & 0.01
\end{tabular}

Notes: Here we report the $p$-values of a likelihood ratio (LR) test on the null hypothesis that the information variable has no explanatory power over the determination of the regime path. In all of these specifications, the information variable is the AA-rated asset of the spliced index.

assets underlying the later issues of the ABX indexes. The deterioration in the quality of subprime mortgages, declines in real estate prices and the increased uncertainty surrounding the associated securitised financial products, impacted greatly on the 2007 issues of the ABX indexes and appear to have acted as a catalyst for the crisis that swept through the financial system. We investigate this hypothesis in more detail below.

The remaining results for the spliced index are similar to before. The start of the crisis period is the same - July 2007 - but its duration is slightly longer, by just a couple of months. It is worth bearing in mind that the entire crisis period is represented by the AAA-rated tranche of the final vintage of the ABX index and all deals underlying this issuance were struck in the first half of 2007. This issue suffered steeper declines than the 2006 issue employed in the previous analysis, which may explain the slightly longer crisis duration between Figs. 2 and 3.

The change in sign for the expected returns and increased volatilities for all assets are again observed as the financial markets transit from "normal" conditions to the high-volatility state (Table 5) and the pattern in correlations is also unchanged (Table 6). More importantly, and despite our reservations about using the spliced series, our conclusions regarding contagion remain unaltered. There is still no evidence of contagion either to or from the subprime mortgage asset-backed market (Table 7). Its role appears to be confined to triggering the crisis episode and then through its interdependence with the other sectors of the U.S. financial system. The same pattern of contagion is also confirmed with evidence of contagion from the liquidity variable to corporate debt and volatility markets and from the VIX to the equity index.

We undertake further analysis to investigate the hypothesis that factors captured by the spliced, but not the ABX 06-1, index (such as declining lending standards and poorer loan quality) are important in triggering the regime switch. We estimate a model with the AAA-rated asset of the continuously traded 06-1 index included in the vector of dependent variables but specify the spliced variable as the information variable governing the regime path. This allows us to shed light on whether or not the difference in results reported above are really driven by the deteriorating conditions in the subprime-mortgage market. Table 8 reports the results of the tests that the information variable has no explanatory power over the determination of regime switches.

Panel A refers to the full six-variable model. Over the whole sample, we fail to find a statistically significant relationship between the spliced information variable and the regime path. Just as in the earlier model with the continuously traded asset, we conclude against the presence of contagion. To gain a better understanding of how the later vintages affect the evolution of regimes, we undertake further analysis by restricting the sample to exclude the earlier issues. For example, we start the sample at July 20,2006 so that the first vintage will be excluded from the spliced variable and repeat the exercise until only the final vintage (07-2) remains. This estimation strategy obviously omits important information from the sample and thus results should be treated with caution. But, it does allow us to assess the importance of later vintages and provides an indication of what may be driving our results. When 2006-issued indices are included in the sample, the information variable does not explain the 
regime switches. However, when the sample begins in 2007 , the later vintages exert a statistically significant influence on the regime path. This provides some evidence that the later vintages of the spliced index help to determine the state of the system.

On balance, we conclude that there is very limited evidence of contagion in our findings. There is no evidence, whatsoever, that the cross-market relationships involving the subprime mortgagebacked market were unstable between regimes. Thus, it would appear that market interdependence, and not contagion, was the main transmission mechanism of the crisis. There is some evidence that the subprime market was a trigger variable for the transition of the financial system to a new bad equilibrium. However, over the full sample, this is limited to the model using spliced indices in the vector of dependent variables and as the information variable. This finding does not hold when the continuously traded asset is used to represent the subprime backed market. Restricting the sample suggests that later vintages are more successful in predicting the regime path but their is influence is diluted in the full time period.

\subsection{Systems of smaller dimension}

Given our results pertaining to the stability of cross-market relationships, a remaining doubt is that our failure to reject the hypothesis of "no contagion" may be due to the large number of parameters that need to be estimated simultaneously. A highly nonlinear model such as the TVTP MS-VAR can be quite sensitive to the inclusion of many variables and lags (Manzan, 2004). The lack of precision of these estimates may result in our model having low power to reject the null hypothesis. We address this potential problem by estimating a range of smaller systems. Of course, we acknowledge that in so doing we may expose ourselves to an omitted variables problem but given the sparse evidence of any cross-market predictability in the six variable model, we proceed to analyse the models of smaller dimension. In particular, we estimate models based on assets from a particular sector of the financial system and, since we are ultimately concerned with measuring contagion from the subprime mortgage asset-backed market, we include the return on the AAA-rated tranche of the January 2006 issue of the ABX index in all specifications. The Libor-OIS spread is also included since the original model identifies this as the main source of contagion. The information variable employed is the return on the traded AA-rated tranche of the 06-1 index. ${ }^{10}$ We deal with each of these sectors in turn and only report the results of our tests for contagion. ${ }^{11}$ Table 9 presents our results.

\subsubsection{Equity markets}

We begin with equity markets and estimate a four variable MS-VAR model with two lags, in which the variables analysed are the return on the S\&P 500 index, the return on S\&P financial index, changes in the Libor-OIS spread and the return on the AAA-rated ABX 06-1 asset. Results are reported in panel A of Table 9. As in the larger model, we find no evidence of either form of contagion. The lagged AA-asset return is unable to predict the regime switch and all relationships involving the subprime mortgage asset-backed market appear stable between regimes. The only evidence of contagion again stems from the Libor-OIS variable and is transmitted to the index of financial stocks, with the liquidity shortage exerting a larger than anticipated negative influence on the financial sector.

\subsubsection{Corporate debt markets}

Again we use a four variable specification. For corporate debt markets, we use the change in the spread over 10-year Treasuries on both the Aaa- and Baa-rated bonds. Results are contained in panel $\mathrm{B}$ of Table 9. Once more, the subprime mortgage-backed asset plays no role in determining the regime path. We detect a statistically significant change in the relationship between the subprime mortgage asset and the Aaa-rated corporate spread. However, upon closer inspection, we find that it is due to a weakening of the relationship between the two assets in the crisis period. The sum of the coefficients

\footnotetext{
${ }^{10}$ For completeness, we re-estimate all models using the spliced AA-rated asset as the information variable. Results are presented Table 8 (Panel B). Since the pattern does not change, we restrict our discussion to the results presented in Table 9.

11 All results are available on request.
} 


\section{Table 9}

Tests for contagion by financial sector: analysis using traded ABX 06-1 index.

\begin{tabular}{lllll}
\hline Panel A: equity market & & & & \\
\hline & $H_{0}:$ & $\theta_{1}=\gamma_{1}=0$ & LR test stat. & 2.44 \\
\hline Contagion from: & ABX & S\&P 500 & S\&P Financials & Libor-OIS \\
To: & & & & 0.40 \\
ABX & - & 0.89 & 0.63 & 0.12 \\
S\&P 500 & 0.69 & - & - & $0.03^{* *}$ \\
S\&P financials & 0.73 & 0.20 & 0.74 & -
\end{tabular}

Panel B: Corporate Debt Market

\begin{tabular}{|c|c|c|c|c|}
\hline & $H_{0}:$ & $\theta_{1}=\gamma_{1}=0$ & LR Test Stat & 3.63 \\
\hline $\begin{array}{l}\text { Contagion from: } \\
\text { To: }\end{array}$ & $\mathrm{ABX}$ & Aaa spread & Baa spread & Libor-OIS \\
\hline$A B X$ & - & 0.69 & 0.59 & 0.70 \\
\hline Aaa spread & $0.02^{* *}$ & - & $0.01^{* * *}$ & $0.07^{*}$ \\
\hline Baa spread & 0.75 & 0.13 & - & $0.03^{* *}$ \\
\hline Libor-OIS & 0.92 & 0.67 & 0.53 & - \\
\hline
\end{tabular}

Panel C: U.S. Treasury market

\begin{tabular}{|c|c|c|c|c|}
\hline & $H_{0}:$ & $\theta_{1}=\gamma_{1}=0$ & LR Test Stat & $5.41^{*}$ \\
\hline $\begin{array}{l}\text { Contagion from: } \\
\text { To: }\end{array}$ & $\mathrm{ABX}$ & One-year Treasury & 10-year Treasury & Libor-OIS \\
\hline$A B X$ & - & 0.89 & 0.33 & 0.70 \\
\hline One-year Treasury & 0.92 & - & 0.92 & $0.03^{* *}$ \\
\hline 10-year Treasury & 0.15 & 0.98 & - & $0.05^{* *}$ \\
\hline Libor-OIS & 0.76 & $0.01^{* * *}$ & $0.10^{*}$ & - \\
\hline
\end{tabular}

Panel D: short-term funding markets

\begin{tabular}{lllll}
\hline & $H_{0}:$ & $\theta_{1}=\gamma_{1}=0$ & LR Test Stat & $27.81^{* * *}$ \\
\hline Contagion from: & ABX & Libor-OIS & ABCP \\
To: & & & \\
ABX & - & 0.68 & 0.38 \\
Libor-OIS & 0.90 & - & $0.02^{* *}$ \\
ABCP & 0.59 & $0.000^{* * *}$ & -
\end{tabular}

Panel E: volatility market

\begin{tabular}{|c|c|c|c|c|}
\hline & $H_{0}:$ & $\theta_{1}=\gamma_{1}=0$ & LR test stat. & $24.15^{* * *}$ \\
\hline $\begin{array}{l}\text { Contagion from: } \\
\text { To: }\end{array}$ & $\mathrm{ABX}$ & VIX & Libor-OIS & \\
\hline$A B X$ & - & 0.30 & 0.63 & \\
\hline VIX & $0.08^{*}$ & - & $0.04^{* *}$ & \\
\hline Libor-OIS & 0.78 & 0.41 & - & \\
\hline
\end{tabular}

For each sector of the financial system, we estimate a separate model as specified in Eqs. (1)-(3). This table presents the main results in Panels A-E. In each panel we initially report the likelihood ratio (LR) test statistic of our test to choose between the FTP model $\left(\theta_{1}=\gamma_{1}=0\right)$ and TVTP model. The remainder of each panel presents $p$-values for tests of contagion between each pair of markets. The null hypothesis is "No Contagion" and implies $\beta_{i j, k}(s=1)=\beta_{i j, k}(s=2)$, where $i$ and $j$ represent the assets under consideration, $k$ the lag and $i \neq j .{ }^{* * *},{ }^{* *},{ }^{*}$ denote significance at the $1 \%, 5 \%$ and $10 \%$ levels, respectively. 
changes from 0.0325 to 0.0075 and, in fact, the coefficient on the second lag is negative for the highvolatility regime. Thus the changing relationship is more consistent with a "flight-to-quality" type effect rather than contagion. It makes sense that investors, keen to flee the asset-backed market, would turn to highly rated corporate debt in a bid to protect their portfolio investments.

Interestingly, we detect uni-directional contagion between the bond classes. Shocks to the Baarated bond result in greater than anticipated responses in its Aaa-rated counterpart. This may be due to decreasing confidence in the ratings or just heightened sensitivity in the latter. There is also evidence of contagion from the liquidity variable to both corporate debt instruments, though the change in the relationship is only marginally significant $(p$-value $=0.07$ ) in the case of Aaa-rated bond. In both cases the spread increases during the crisis as pressure on short-term funds adversely affected the corporate debt market more than could have been expected during "normal" financial market conditions.

\subsubsection{U.S. Treasury market}

In analysing the relationship between the subprime mortgage-backed market, the Libor-OIS, and the market for U.S. Treasuries, we capture both the short- and long-end of the U.S. Treasury yield curve by including both the daily change in the rate on one-year and 10-year Treasuries. Panel C of Table 9 displays our results. Interestingly the information variable becomes marginally significant here. In the smaller system without equity or corporate debt variables, the lagged ABX variable helps to predict the evolution of the regime path. This is a feature of the reduced-dimension models that exclude corporate funding markets. Once more, cross-market relationships involving the subprime-backed asset appear stable between regimes and hence we find no support for the correlation channel of contagion. This is in contrast to the liquidity variable whose relationship with both of the Treasury instruments changes between regimes. The pattern of change is interesting with the relationship between Libor-OIS and the shorter-term instrument becoming significantly more negative. This implies that liquidity shortages led to greater than expected cuts in the one-year Treasury rates as the Federal Reserve aggressively cut rates in an effort to combat the developing crisis. On the other hand, the Libor-OIS and 10-year Treasury relationship becomes less negative, suggesting that liquidity shortages did not impact on the longer-maturity bonds as much as expected. The falls in the long rates were less than predicted by "normal" market relationships and may have been offset by the increasing economic risk. This shows an important distinction between the sensitivity of shortand long-term Treasuries to liquidity shocks. Of further interest is that the relationship changes are bi-directional. Again, there are subtle differences in the way Libor-OIS responds to shocks in Treasuries of different maturities. The response of the liquidity variable to a cut in the one-year rate becomes significantly more negative, suggesting that surprise cuts at the short end of the Treasury curve did not have the desired effect of restoring liquidity to the banking sector. In contrast, changes in the 10-year Treasury rate have no effect on Libor-OIS during the high-volatility regime, again reinforcing the idea that changes to long rates are ineffective during a liquidity shortfall. The failure of Treasury rate cuts to reverse liquidity is probably due to the uncertainty that often surrounded government policy during the turbulent period and the ensuing hoarding of liquid assets that took place by many financial institutions.

\subsubsection{Short-term liquidity markets}

A trivariate MS-VAR is employed to assess the stability of linkages between the subprime mortgage asset-backed market, the Libor-OIS spread and the market for 30-day ABCP. The latter two variables are selected for their ability to capture liquidity conditions in the financial markets. We document our results in Panel D of Table 9. Interestingly, there is no evidence of changing relationships involving the $\mathrm{ABX}$ asset but there is strong bi-directional evidence of contagion between the two liquidity markets. Adverse liquidity shocks produce positive and higher than anticipated changes to the rates on 30-day $A B C P$, while adverse shocks to the ABCP market lead to greater impairment of the interbank market than predicted by "normal" market relationships. The reinforcing effects of these two markets are consistent with the severe liquidity shortages experienced in the market, especially after the collapse of Lehman Brothers in September 2008. 


\subsubsection{Volatility market}

Finally, we estimate a trivariate model of ABX returns, Libor-OIS, and the change in the VIX index. Panel E of Table 9 presents our findings. Here we find the only evidence of contagious effects from the subprime mortgage-backed asset, although it is only marginally significant with a $p$-value of 0.08 . Therefore the only direct evidence of correlation contagion from this sector appears to be a relatively weak transmission of excess future economic uncertainty as implied by option prices. Again we find evidence of contagion from the liquidity market to the VIX. All other relationships are stable between regimes.

The pattern that emerges from this analysis is that the subprime mortgage-backed market played little role in causing the financial crisis. Once corporate equity or debt is incorporated into the system, the effect of the ABX variable is subsumed and plays no role in driving the system to the high-volatility regime. Likewise for the correlation channel, there is little evidence that it transmitted contagious effects to other markets, with possibly the exception of the volatility market. Its relationships with other sectors of the U.S. financial system remained stable between regimes and therefore we conclude that it was interdependence between markets that propagated the initial shock across the system. Interestingly, the liquidity variable generates most evidence of contagion. Its relationships often change as markets transit from a "normal" to a high-volatility regime. Thus, the excessive or unpredictable reaction of the other sectors during the crisis period appears to be predominantly driven by shocks to liquidity markets rather than the market for subprime mortgage-backed securities.

\section{Conclusions}

We analyse the role of the subprime mortgage-backed market in causing the widespread turmoil experienced in the U.S. financial system from 2007 to 2009. We employ a TVTP MS-VAR methodology which allows us to assess pairwise relationships across various sectors of the financial system. We analyse two forms of contagion; firstly, contagion that gives rise to statistically significant changes in cross-market relationships between the crisis and the non-crisis regimes and secondly contagion that results from a particular variable driving the system to a new (bad) equilibrium. A number of striking findings emerge from the study. Firstly, we find little or no evidence of contagion through the correlation channel emanating from the subprime mortgage-backed market. Over a variety of model specifications and robustness checks, we consistently fail to find evidence of a statistically significant change in the relationships between this market and other sectors of the financial system. Initially, this may seem surprising. However, the crashes in other markets appear to be a consequence of the high degree of interdependence in the financial system rather than any excessive reaction to the shock in the subprime asset-backed sector. Secondly, where any contagion is detected it tends to originate from our liquidity variables, the Libor-OIS spread and/or the change in the 30-day ABCP rate. Previously, liquidity problems in the aftermath of the collapse of Lehman Brothers have been attributed to transmitting the crisis internationally (Aït-Sahalia, Andritzky, Jobst, Nowak, \& Tamirisa, 2009; Brunnermeier, 2008; among others) but here we show that shocks to liquidity variables were also instrumental in exacerbating the crisis across the U.S. financial system. Thirdly, there is limited evidence that deteriorating conditions in the subprime mortgage-backed market helped to predict the transition between regimes. However this result is not consistent across model specifications and, over the full sample, only applies to models that employ the spliced index and not the actual traded asset.

\section{Acknowledgements}

We thank the anonymous referee for helpful comments and suggestions which improved the paper. We also thank Professor Mardi Dungey of the University of Tasmania and other participants at the Financial Crises conference at Maynooth University for useful comments and suggestions. Finally we thank Professor Marcus Miller of the University of Warwick, Professor Gregory Connor of Maynooth University and Professor Stephen Thomas of Cass Business School for their helpful comments and suggestions. 


\section{References}

Aït-Sahalia, Y., Andritzky, J., Jobst, A., Nowak, S., \& Tamirisa, N. (2009). How to stop a herd of running bears. Market response to policy initiatives during the global financial crisis. IMF Working Paper, No. WP/09/204.

Brière, M., Chapelle, A., \& Szafarz, A. (2012). No contagion, only globalization and flight to quality. Journal of International Money and Finance, 31(6), 1729-1744.

Brunnermeier, M. K. (2008). Deciphering - The liquidity and credit crunch 2007-2008, National Bureau of Economic Research (NBER), Working Paper No. 14612.

Brunetti, C., Scotti, C., Mariano, R. S., \& Tan, A. H. (2008). Markov switching GARCH models of currency turmoil in southeast Asia. Emerging Markets Review, 9(2), 104-128.

Claessens, S., Dornbusch, R., \& Park, Y. (2000). Contagion: understanding how it spreads. The World Bank Research, 15(2), $177-197$.

Demyanyk, Y., \& Van Hemert, O. (2011). Understanding the subprime mortgage crisis. Review of Financial Studies, 24, $1848-1880$.

Dungey, M., Dwyer, G., \& Flavin, T. J. (2013). Systematic and liquidity risk in subprime-mortgage backed securities. Open Economies Review, 24, 5-32.

Dungey, M., Fry, R., González-Hermosillo, B., \& Martin, V. (2010). Transmission of financial crises and contagion: A latent factor approach. New York: Oxford University Press.

Dungey, M., Fry, R., González-Hermosillo, B., Martin, V., \& Tang, C. (2009). Are financial crises alike? IMF Working Paper, No. WP/10/14.

Dwyer, G., \& Tkac, P. (2009). The financial crisis of 2008 in fixed-income markets. Journal of International Money and Finance, 28, 1293-1316.

Fender, I., \& Scheicher, M. (2008, September). The ABX: How do markets price subprime mortgage risk? Bank for International Settlements (BIS) Quarterly Review.

Filardo, A. J. (1994). Business-cycle phases and their transitional dynamics. Journal of Business and Economic Statistics, 12(3), 299-308.

Filardo, A. J. (1998). Choosing information variables for transition probabilities in a time-varying transition probability Markov switching model. Federal Reserve Bank of Kansas City, Working Paper, RWP 98-09.

Flavin, T. J., \& Panopoulou, E. (2010). Detecting shift and pure contagion in East Asian equity markets: A unified approach. Pacific Economic Review, 15(3), 401-421.

Forbes, K. (2012). The "Big C": Identifying contagion. National Bureau of Economic Research (NBER), Working Paper No. 18465.

Forbes, K., \& Rigobon, R. (2002). No contagion, only interdependence: Measuring stock market co-movements. Journal of Finance, 57(5), 2223-2261.

Gorton, G. B. (2009). Information, liquidity, and the (ongoing) panic of 2007. National Bureau of Economic Research (NBER), Working Paper No. 14649.

Gravelle, T., Kichian, M., \& Morley, J. (2006). Detecting shift-contagion in currency and bond markets. Journal of International Economics, 68(2), 409-423.

Guo, F., Chen, C., \& Huang, Y. S. (2011). Markets contagion during financial crisis: A regime switching approach. International Review of Economics and Finance, 20(1), 95-109.

Hamilton, J. D. (1989). A new approach to the economic analysis of nonstationary time series and the business cycle. Econometrica, 57, 357-384.

Hamilton, J. D. (1990). Analysis of time series subject to changes in regimes. Journal of Econometrics, 45(1), 39-70.

Hamilton, J. D. (1994). Time series analysis. Princeton: Princeton University Press.

Hatemi-J, A., \& Roca, E. (2011). How globally contagious was the recent US real estate market crisis? Evidence based on a new contagion test. Economic Modelling, 28(6), 2560-2565.

Hellwig, M. (2009). Systemic risk in the financial sector: An analysis of the subprime mortgage financial crisis. De Economist, $157(2), 129-207$.

Jeanne, O., \& Masson, P. (2000). Currency crises, sunspots and Markov-switching regimes. Journal of International Economics, $50(2), 327-350$.

Kim, C-J. (1994). Dynamic linear models with Markov switching. Journal of Econometrics, 60(1), 1-22.

Longstaff, F. (2010). The subprime credit crisis and contagion in financial markets. Journal of Financial Economics, 97(3), 436-450.

Mandilaras, A., \& Bird, G. (2010). A Markov switching analysis of contagion in the EMS. Journal of International Money and Finance, 29(6), 1062-1075.

Manzan, S. (2004). Model selection for nonlinear time series. Empirical Economics, 29(4), 901-920.

Masson, P. (1999a]). Contagion: monsoonal effects, spillovers and jumps between multiple equilibria. In P. Agénor, M. Miller, D. Vines, \& A. Weber (Eds.), The Asian financial crisis: Causes, contagion and consequences. Cambridge, UK: Cambridge University Press.

Masson, P. (1999b]). Contagion: Macroeconomic models with multiple equilibria. Journal of International Money and Finance, $18(4), 587-602$

Mian, A., \& Sufi, A. (2009). The consequences of mortgage credit expansion: Evidence from the U.S. mortgage default crisis. Quarterly Journal of Economics, 124(4), 1449-1496.

Park, S. Y.(2010). The design of subprime mortgage-backed securities and information insensitivity. Yale University (Working Paper).

Peria, M. S. M. (2002). A regime-switching approach to the study of speculative attacks: A focus on EMS crises. Empirical Economics, 27(2), 299-334.

Shin, H. S. (2012). Global banking glut and loan risk premium. IMF Economic Review, 60(2), 155-192.

Stanton, R., \& Wallace, N. (2011). The bear's lair: Index credit default swaps and the subprime mortgage crisis. Review of Financial Studies, 24(10), 3250-3280.

Van Wincoop, E. (2011). International contagion through leveraged financial institutions. National Bureau of Economic Research (NBER), Working Paper No. 17686. 